\title{
Bone mineral density and nutritional status of postmenopausal women
}

See end of the paper for authors' affiliations

\section{LATA KUSUM}

Department of Dietetics, Brahm Shakti Hospital, DELHI, INDIA Email : kusum.delhi@gmail.com
-ABSTRACT : The study was carried out to assess the nutrient intake and to identify errors in dietary habits of postmenopausal women with special relevance to bone health. Another purpose of the study was to assess their lifestyle habits including physical activity and sun- exposure. Thirty seven women aged 45 to 60 years were enrolled according to the inclusion and exclusion criteria stated in the study. Data analysis revealed that as per World Health Organization standards 75.68 per cent (28) women had normal BMD, 18.92 per cent (7) had osteopenia and 5.41 per cent (2) women were suffering from osteoporosis. Intake of energy, protein, visible fat, invisible fat, calcium, phosphorus, iron, magnesium, vitamin $\mathrm{A}$, vitamin $\mathrm{D}$, vitamin $\mathrm{E}$, vitamin $\mathrm{K}$ were below the RDA (India) in the diets of about 59.46 per cent (22), 37.84 per cent (14), 29.73 per cent (11), 5.41 per cent (2), 16.22 per cent (6), 0 per cent, 59.46 per cent (22), 18.92 per cent (7), 100 per cent (37), 86.49 per cent (32), 75.68 per cent (28), 2.70 per cent (1) women, respectively.59.46 per cent (22) women were taking nutrient supplements i.e. calcium, vitamin D and multivitamins. 16.22 per cent (6) women had deficient calcium status; they were consuming significantly low dietary calcium and were not taking calcium supplements. It was found that, except 36.36 per cent (8) women (those taking Vitamin D supplements); all were deficient in vitamin D. Several reasons/ causes for lower physical activity or disinterest in regular exercise were identified. 29.73 per cent (11) postmenopausal women experienced discomfort while walking. Sub-optimal nutritional status could be one of the major contributory factor of poor bone health. In the absence of balanced diet and sun exposure, nutrient supplements become necessary to support bone health of postmenopausal women.

KEY WORDS: Bone mineral density, Osteoporosis, Postmenopausal women, Serum vitamin $\mathrm{D}$, Anthropometric measurements

- HOW TO CITE THIS PAPER : Lata, Kusum and Suri, Sukhneet (2015). Bone mineral density and nutritional status of postmenopausal women. Asian J. Home Sci., 10 (2) : 342-352. 